\title{
Voluminous Community-Acquired Methicillin-Resistant Staphylococcal Pleuropneumonia in a Cameroonian Child
}

\author{
Georges Pius Kamsu Moyo", Raymond Ndikontar, Dany Hermann Ngwanou, Nelly Guimeya, \\ Jacqueline Ze Minkande \\ Faculty of Medicine and Biomedical Sciences, The University of Yaoundé I, Yaoundé, Cameroon
}

*Corresponding Author: Georges Pius Kamsu Moyo, Faculty of Medicine and Biomedical Sciences, The University of Yaoundé I, Yaoundé, Cameroon, E-mail: kamsuzicfried@yahoo.fr

\begin{abstract}
Pneumonia and its complications are a major cause of child mortality worldwide. In developing countries, Progressive immunization against $S$. pneumoniae and $H$. influenzae which are major causative agents, may coincide with the emergence of staphylococcal pleuropneumonia as part of "replacement phenomenon". Community-acquired methicillin-resistant staphylococcus aureus is relatively rare and may be particularly difficult to treat. There are hypotheses over genetic influences as far as the onset, progress and severity of pleuropneumonia or empyema thoracis in children is concerned. We present and discuss base on literature review the case of a 19-months-old Cameroonian male child who was admitted for severe pneumonia from physical examination. In whom complementary exams permitted to conclude as loculated communityacquired methicillin-resistant staphylococcal pleuropneumonia of rapid onset, based on chest $x$-ray, ultrasound and pleural fluid culture. The patient was isolated, treated exclusively by intravenous antibiotic therapy with vancomycin and supportive care. The evolution was favourable, with recovery after 5 weeks of hospitalization. Therefore, voluminous loculated pleuropneumonia may be caused by uncommon pathogens such as community-acquired MRSA, especially in cases where there is rapid onset of complications. Physical examination, aided by radiological and blood or pleural fluid culture may be necessary for accurate diagnosis. The treatment may be exclusively medical with complete recovery.
\end{abstract}

Keywords: Staphylococcus, MRSA, pleuropneumonia, empyemathoracis

\section{BACKGROUND}

The prevalence of community-acquired pneumonia (CAP) and complications is high in developing countries including Cameroon, with close to 151 million new cases every year in children aged less than 5 years [1,2]. Its mortality rate lies between $1.3-2.6 \%$ [1,2] Pleuropneumonia or empyema thorasis is an uncommon and particular complication of childhood pneumonia and some physicians may only see few cases in their career [3]. The reported incidence worldwide lies between 0.7 and 3.3 per 100000 children [3,4]. Unlike adults in whom mortality due to empyema could be as high as $20 \%$, children rarely die of empyema. However, it is associated with significant morbidity and sustained burden to health care resources [5, 6]. In effect, the incidence of childhood hospitalization due to CAP is $8.7 \%$ in developing countries, of which $75 \%$ have severe or very severe pneumonia according to World Health Organization (WHO) classification [7, 8,
9]. The risk factors identified are malnutrition, crowding, low birth weight, low level of immunization, vitamin A deficiency, smoking, HIV [1,7]. Despite preventive measures such as encouraged breastfeeding, immunization, vitamin A supplementation andantibiotic therapy, recent data suggest that the number of children with severe CAP and complications including pleuropneumonia are increasing world wide [10]. This may be due to uncovered germs by immunization, a process known as "replacement phenomenon" [10]. Therefore, there is need for research in various areas including aetiologies, complications and contextualised evidence-based recommendations for management [10]. Systematic reviews have revealed Staphylocaccus aureus along side Streptococcus pneumoniae and Hemophilus influenzae as the most frequently cultured bacteria in severe pediatric cases of CAP and complications $[11,12]$. We present a case of community acquired methicillin-resistant 
staphylococcal pleuropneumonia with rapid onset in a Cameroonian child.

\section{CASE REPORT}

This is the case of a 19 months old male toddler who presented with a history of fever, cough and dyspnea evolving for 6 days. The child's past history revealed parental smoking, notion of pustular rash the preceding week, up to date immunization status, exclusive breastfeeding up to six months and the child was living with his parents only. On physical examination, the temperature was $39.5^{\circ} \mathrm{c}$, the breathing rate was 56 cycles/min, blood oxygen saturation was $75 \%$. The child was pale with nasal flaring, grunting and lower chest wall in drawing. There were decreased unilateral chest expansion, decreased tactile fremitus, with an associated stony dull percussion and reduced breath sounds on the right side of the thorax.

Complementary exams revealed abnormal laboratory findings with leucocytosis at $17000 / \mathrm{mm}^{3}$ and granulocytes predominating, moderate normocytic normochromic anemia at $7.5 \mathrm{~g} / \mathrm{dl}$, elevated CRP at $90 \mathrm{mg} / \mathrm{l}$. The chest $\mathrm{x}$ ray showed massive homogenous opacification of more than two-third of the right hemithorax with a retracted right lung.

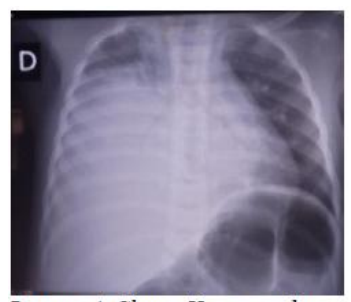

Image 1.Chest X-ray under a negatoscope showing massive opaque right hemithorax

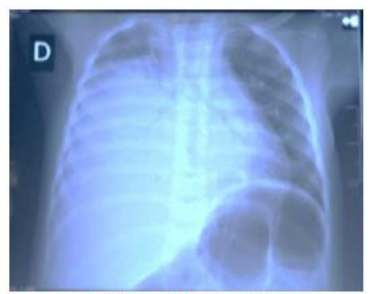

Image 2. Chest X-ray without a negatoscope showing retracted right lung

The pleural echography showed right lung panlobar consolidation with bronchogram and encystment, with apical pleural effusion of about $165 \mathrm{ml}$. These findings were in favor of loculated or organized pleuropneumonia of great abundance.

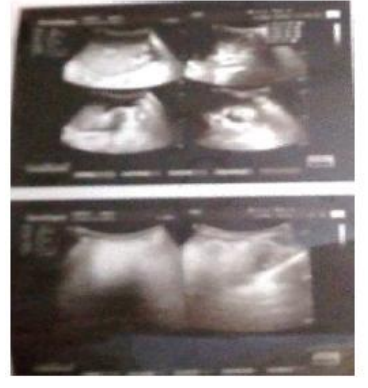

Image3. Panlobar consolidation with bronchogram
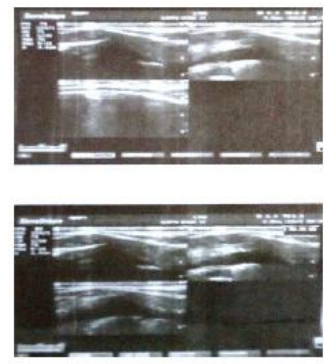

Image 4. Voluninous pleural effusion with encystment
Blood culture was negative, but purulent pleural fluid culture obtained by thoracentesis of about $5 \mathrm{cc}$ in the larger pouch isolated methicillinresistant Staphylococcus aureus (MRSA) that was sensitive to vancomycin.

The child was isolated, put on oxygen at $31 / \mathrm{min}$ through a nasal prong, intravenous fluids were estimated at $1100 \mathrm{ml}$ per day according to Holliday Segar method, including normal saline, dextrose $10 \%$ and packed red blood cells at 90 $\mathrm{ml}$. Paracetamol and Vancomycin were administered at $15 \mathrm{mg} / \mathrm{kg}$ every 6 hours. The child was placed on scope for monitoring of vital parameters, and the diuresis was equally followed up. The antibiotic therapy with intravenous Vancomycin lasted for 5 weeks. The Evolution was favorable as from the $3^{\text {rd }}$ week, with a patient who was no more oxygen dependent, the fever disappeared and the child could feed normally.

\section{DISCUSSION}

In children with severe or complicated forms of CAP, the main criteria for hospitalisation are clinical according to WHO's classification, and mainly when blood oxygen saturation $\left(\mathrm{SPO}_{2}\right)$ is $<92 \%$ and patient isolation may be recommended to avoid intra-hospital contamination spread $[13,8,9]$. This may be due to the fact that the risk of death is 1.4-4.6 times higher in children presenting hypoxia than those without $[14,15]$.

Despite the fact that radiological imaging may be evocative as far as the degree of severity is concerned, they may not always be available especially in limited resource settings $[10,16$, 17]. In the present case, the patient had an $\mathrm{SPO}_{2}$ at $75 \%$ and an altered general state that were quite expressive and so hospitalisation seemed justified.

Clinically, pleuropneumonia may be confused with severe pneumonia as they may have in common respiratory signs and symptoms, consolidation syndrome, and contrasting only with pleural effusion that often develop progressively. In the present case, the effusion syndrome appeared to be of rapid onset compared to the six-day history of illness reported, perhaps because of genetic influences $[18,19]$.

Radiological imaging by chest X-ray and echography have a major role in the diagnosis of pleuropneumonia as they give clues on the severity and etiological orientations, while CT- 
scan may be reserved for severe or surgical cases $[20,10]$. Our patient had significant radiological findings which made diagnosis easier. Nevertheless, blood and pleural fluid culture might be the only exams to conclude on causative bacteria, though a pathogen might not be isolated, given most empyema may contain marginal amount of cells and not be contaminated [1, 21, 22].

Although the most severe and complicated CAP are caused by bacteria, MRSA may rarely be found as Streptococcus pneumoniae, Haemophilus influenzae and common Staphylococcus aureus are predominant [1,7]. MRSA may be nosocomial or community acquired, depending on its incidence in the area where the infection occurs [10]. In effect, MRSA treatment might be envisaged when its incidence exceeds $20 \%$ [10]. In such patients an entry point from which the infection develops may be found. This was the case in our patient who had a past history of pustular rash, which was manifested some days before the onset of respiratory symptoms.

Vancomycin which served as main treatment is effective and indicated against MRSA, contrarily to cloxacillin to which the bacterium is usually resistant [10]. Objectives in treating empyema are to sterilize the pleural fluid and restore lung function, and may last for up to 6 weeks $[10,8]$. Intercostal drainage which might have helped for rapid recovery could not be applied in this case because of multiple loculation for which repeated punctures are likely to be traumatic [23, 10]. Fibrinolytics advocated by some authors, may not be compulsory given that there seems not to be considerable patient amelioration due to this procedure [24]. Video assisted thoracostomy (VATS) could neither be practiced because of unavailability $[25,26]$. Physiotherapy was not practiced because of the patient's instability at the beginning, and later on due to family refusal $[27,28]$. Oxygen therapy is recommended until $\mathrm{SpO}_{2}$ remains stable beyond $92 \%$ and total fluids calculated may be majored because of increased losses due to fever and elevated breathing rate $[13,10]$.

Keen monitoring of vital parameters and urinary outputs is necessary especially in voluminous pleuropneumonia where hemodynamic alterations can occur as a result of septic shock, pericardial effusion, cardiac tamponade or inappropriate secretion of antidiuretic hormone $[23,29,30]$. Early discharge is encouraged as soon as the patient is stable, strong enough and can feed normally, in order to limit nosocomial infections and healthcare cost[10].

\section{CONCLUSION}

Voluminous loculated pleuropneumonia may be caused by uncommon pathogens such as community acquired MRSA especially in cases where there is rapid onset of complications. Physical examination aided by radiological and blood or pleural fluid culture may be necessary for accurate diagnosis. Although a considerable proportion of children with pleuropneumonia may fail to respond to treatment, pathogen identification and antibiogram may improve the management. Well adapted antibiotic therapy and efficient supportive care may be sufficient regardless of drainage, physiotherapy, fibrinolytics and thoracostomy which are not always applicable.

\section{REFERENCES}

[1] Ranganathan SC, Sonnappa S. Pneumonia and other respiratory infections. Pediatr Clin North Am $2009 ; 56: 135 \mathrm{e} 56$.

[2] Chisti MJ, Tebruegge M, La Vincente S, Graham SM, Duke T. Pneumonia in severely malnourished children in developing countries-mortality risk, aetiology and validity of WHO clinical signs: a systematic review. Trop Med Int Health 2009; 14:1173e89.

[3] Strachan RE, Jaffe A. Assessment of the burden of paediatric empyema in Australia. J Paediatr Child Health2009 ; 45 :431-436.

[4] Jaffe A, Balfour-Lynn IM. Management of empyema in children. Pediatr Pulmonol 2005; 40(2):148-56.

[5] Shah SS, Ten Have TR, Metlay JP. Costs of treating children with complicated pneumonia: a comparison of primary video-assisted thoracoscopic surgery and chest tube placement. PediatrPulmonol 2010;45(1):71-77.

[6] St Peter SD, Tsao K, Harrison C et al. Thoracoscopic decortication vs tube thoracostomy with fibrinolysis for empyema in children: a prospective, randomized trial. J PediatrSurg 2009; 44(1):106-111.

[7] Rudan I, Boschi-Pinto C, Biloglav Z, Mulholland K, Campbell H. Epidemiology and etiology of childhood pneumonia. Bull World Health Organ 2008; 86:408e16.

[8] World Health Organization. Pocket Book of Hospital Care for Children. Guidelines for the 
Management of Common Illnesses with Limited Resources. WHO Press, 2005:72e81.

[9] Tupasi TE, Velmonte MA, Sanvictores ME, Abraham L, De leon LE, Tan SA et al. Determinants of morbidity and mortality due to acute respiratory infections: implications for interventions. J Infect Dis 1988; 157:615e23.

[10] Principi N, Esposito S. Management of severe community-acquired pneumonia of children in developing and developed countries Thorax 2011; 66:815e822.

[11] Jansen AG, Sanders EA, Hoes AW, Van loon AM, Hak E. Influenza- and respiratory syncytial virus associated mortality and hospitalizations. EurRespir J 2007; 30:1158e66.

[12] Vuori-Holopainen E, Salo E, Saxen H,Hedman $\mathrm{K}$, HyypiaT et al. Etiologic diagnosis of childhoodpneumonia by use of transthoracic needle aspiration and modern microbiological methods. Clin Infect Dis 2002; 34:583e90.

[13] British Thoracic Society of Standards of Care Committee. BTS guidelines for the management of community acquired pneumonia in childhood. Thorax 2002; 57: i1e24.

[14] De Schutter ID, Malfroot A, Pie'rard D, et al.Pneumococcal serogroups and serotypes in severe pneumococcal pneumonia in Belgian children: theoretical coverage of the 7-valent and 9-valent pneumococcal conjugate vaccine. PediatrPulmonol2006; 41:765e70.

[15] Tiewsoh K, Lodha R, Pandey RM, et al.Factors determining the outcome of children hospitalized with severe pneumonia. BMC Pediatr2009; 9:15.

[16] Principi N, Esposito S. Emerging role of Mycoplasma pneumoniae and Chlamydia pneumoniae in paediatric respiratory tract infections. Lancet Infect Dis 2001; 1:334e44.

[17] Key VK, Arau jo-Neto CA, NascimentoCarvalho CM. Severity of childhood community-acquired pneumonia and chest radiographic findings. PediatrPulmonol2009; 44:249e52.

[18] Quadri A, Thomson AH. Large pleural effusion. PaediatrRespirRev2002 ; 3(4) :357, 360.
[19] Roy S, Knox K, Segal S, Griffiths D, Moore $\mathrm{CE}$, Welsh KI et al. MBL genotype and risk of invasive pneumococcal disease: a case-control study. Lancet 2002; 359(9317):1569-1573.

[20] Massie J, Pillarisetti N, Ranganathan S. No role for routine CT scans in paediatric empyemas. Thorax 2008; 63(11):1028-1029.

[21] Atkinson M, Yanney M, Stephenson T, Smyth A. Effective treatment strategies for paediatric community acquired pneumonia. Expert OpinPharmacother2007; 8:1091e101.

[22] Tan TQ, Mason EO Jr, Wald ER,Barson WJ, Schutze GE, Bradley GS et al. Clinical characteristics of children with complicated pneumonia caused by Streptococcus pneumoniae. Pediatrics 2002; 110:1e6.

[23] Proesmans M, De Boeck K. Clinical practice: treatment of childhood empyema. Eur J Pediatr2009; 168:639e45

[24] Aydigan N, Aydigan A, Ozcan A, Tugay M, Gokalp AS, Arisoy ES. Intrapleural streptokinase treatment in children with empyema. Eur J Pediatr2008; 167:739e44.

[25] Avansino JR, Goldman B, Sawin RS, Flum DR. Primary operative versus nonoperative therapy for pediatric empyema: a meta-analysis. Pediatrics2005; 115:1652e9.

[26] Sonnappa S, Cohen G, Owens CM, Van Doorn C, Carins J, Stanojevic S et al. Comparison of urokinase and video assisted thoracoscopic surgery for treatment of childhood empyema. Am J RespirCrit Care Med 2006; 174:221e7.

[27] Balachandran A, Shivbalan S, Thangavelu S. Chest physiotherapy in pediatric practice. Indian Pediatr2005; 42:559e68.

[28] Wallis C, Prasad A. Who needs physiotherapy? Moving from anecdote to evidence. Arch Dis Child 1999; 80:393e7.

[29] Roberts JE, Bezack BJ, Winger DI, Pollac S, Sah RA, cataletto M, et al.Association between parapneumonic effusion and pericardial effusion in a pediatric cohort. Pediatrics 2008; 122: e1231e5.

[30] Dhawan A, Narang A, Singhi S.Hyponatraemia and the inappropriate $\mathrm{ADH}$ syndrome in pneumonia. Ann Trop Paediatr1992; 12:455e62.

Citation: Georges Pius Kamsu Moyo et al. Voluminous Community-Acquired Methicillin-Resistant Staphylococcal Pleuropneumonia in a Cameroonian Child. ARC Journal of Pediatrics.2020; 6(1):15-18. doi:dx.doi.org/ 10.2043 1/2455-5711.0601004.

Copyright: (C) 2020 Authors. This is an open-access article distributed under the terms of the Creative Commons Attribution License, which permits unrestricted use, distribution, and reproduction in any medium, provided the original author and source are credited. 